\title{
Dyslipidemia: A Cardiovascular Risk Factor in Type 1 Diabetes and Its Correlations
}

\author{
Mona M Hassan, Sahar A Sharaf, Hend M Soliman* and Nanees A Al-Wakeel
}

Diabetes Endocrine and Metabolism Pediatric Unit (DEMPU), New Children Hospital, Cairo University, Cairo, Egypt

\begin{abstract}
Background: The prevalence of T1DM is increasing markedly. It is suggested that it will be an epidemic of type 1 diabetes (T1DM) by 2025. T1DM is a major risk factor for CVD. The mortality and morbidity of CVD are markedly increased in diabetic individuals compared with the non-diabetic population Dyslipidemia is a preventable cause of CVD.

Objective: To evaluate the pattern of dyslipidemia in Egyptian children and adolescents with type 1 DM (T1DM), to study the correlations between different lipid parameters and different variables in the study, in addition to estimate the predictable cardiovascular risk in the study group through calculation of different lipoprotein risk ratios as predictive values of cardiovascular risk.

Methods: In this cross-sectional study, fasting lipid profile was done for sixty patients with T1DM (34 males and 26 females, with a mean age of $12.5 \pm 2.4$ years) and different lipid parameters were correlated to different variables

Results: The most common abnormality was high LDL-C either alone or in combination with other parameters $(50 \%)$. Regarding LDL-C of the patients, there was a positive significant correlation with their $B M I(p=0.039, r=0.268)$ while the correlation with WC was of borderline significance $(p=0.061, r=0.243)$. There was a significant positive correlation between WC and the insulin dosage, BMI and BMI SDS and a positive significant correlation between TG and the age $(p=0.048, r=0.256)$. There were $46.2 \%$ of the dyslipidemic patients at risk of developing CVD according to TC/HDL-C ratio (Castelli index I) and 20.5\% according to LDL-C/HDL-C ratio (Castelli index II).

Conclusion: The most common abnormality was high LDL-C (50\%). There was a positive correlation between LDL-C and BMI and WC. The risk for developing CVD was $46.2 \%$ according to TC/HDL-C ratio (Castelli index I) and $20.5 \%$ according to LDL-C/HDL-C ratio (Castelli index II).
\end{abstract}

Keywords: Type 1 diabetes; Dyslipidemia; LDL-C; Cardiovascular risk; Lipoprotein correlations; Waist circumference (WC); Lipoprotein risk ratios

\section{Background}

Diabetes is a major risk factor for cardiovascular disease (CVD). In patients with T1DM, atherosclerosis can occur earlier in life, leading to increased morbidity and mortality compared with that noticed in the general population [1].

Dyslipidemia is a preventable major risk factor for CVD. There are several studies that have evaluated dyslipidemia in patients with type 2 diabetes mellitus (T2DM), but dyslipidemia in patients with T1DM and especially young children with short duration of diabetes remains largely undiagnosed and undertreated $[2,3]$.

LDL-C is a strong risk factor for CAD, but, it is not only the amount of LDL-C that is important but also the type of LDL-C. Small dense LDL-C is more atherogenic or more injurious to the endothelium than large buoyant LDL-C [4].

\section{Objectives}

To evaluate the pattern of dyslipidemia in Egyptian children and adolescents with type $1 \mathrm{DM}$ (T1DM), to evaluate the correlations between different lipid parameters and anthropometric measures, waist circumference, glycemic control and other variables in the study, in addition to estimate the predictable cardiovascular risk in the study group through calculation of different lipoprotein risk ratios as predictive values of cardiovascular risk.

\section{Material and Methods}

\section{Study population}

The current study was conducted on 60 children and adolescents regularly followed at the Diabetes Endocrine and Metabolism Pediatric Unit (DEMPU), Children's Hospital, Cairo University during the period from May to November, 2012. Subjects were included if they have type 1 diabetes mellitus (T1DM) for one year or more and they were between 9 and 15 years old. Exclusion criteria were associated hypothyroidism and the use of thyroxin therapy or lipid lowering medications. Informed consent was taken from the parents.

\section{Procedures}

Detailed medical history was reported including; the current age, duration of diabetes, age at onset, type and dose of insulin, detailed dietetic history in addition to family history of diabetes, hypertension,

${ }^{*}$ Corresponding author: Soliman $\mathrm{M}$ Hend, New Children Hospital (Abu El Reesh) Cairo University Hospitals, PO Box 2398, Cairo, Egypt, Tel: +201143156468; E-mail: ziad.alaa@yahoo.com

Received June 18, 2015; Accepted July 13, 2015; Published July 17, 2015

Citation: Hassan MM, Sharaf SA, Soliman HM, AI-Wakeel NA (2015) Dyslipidemia: A Cardiovascular Risk Factor in Type 1 Diabetes and Its Correlations. J Diabetes Metab 6: 586. doi:10.4172/2155-6156.1000586

Copyright: $\odot 2015$ Mona HM, et al. This is an open-access article distributed unde the terms of the Creative Commons Attribution License, which permits unrestricted use, distribution, and reproduction in any medium, provided the original author and source are credited. 
Citation: Hassan MM, Sharaf SA, Soliman HM, Al-Wakeel NA (2015) Dyslipidemia: A Cardiovascular Risk Factor in Type 1 Diabetes and Its Correlations. J Diabetes Metab 6: 586. doi:10.4172/2155-6156.1000586

Page 2 of 5

coronary heart disease or stroke, and history suggestive of diabetic microvascular and macrovascular complications.

- $\quad$ All patients were subjected to thorough clinical examination laying stress on anthropometric measures and waist circumference.

- According to the World Health Organization (WHO) growth reference data; Normal BMI is between +1 to $-2 \mathrm{SD},<+1$ SD is considered overweight and $<+2$ SD is considered obese [5].

- Glycemic control was assessed by calculating the mean fasting and $2 \mathrm{hrs}$ postprandial blood glucose (PPBG) for one month preceding the study, and the mean glycosylated hemoglobin (HbAlc) over the last year prior to the study.

- Laboratory assessment was done for fasting lipid profile, including: serum total cholesterol (TC), serum triglycerides (TG), high density lipoprotein-cholesterol (HDL-C) and low density lipoproteincholesterol (LDL-C).

- Different lipid parameters including fasting levels of total cholesterol (TC), triglycerides (TG), high density lipoproteincholesterol (HDL-C) and low density lipoprotein-cholesterol (LDL-C), were correlated to anthropometric measures, age, duration of diabetes, insulin dose, BMI, BMI SDS, WC, mean HbAlc, mean PPBG, mean FBG in addition to dietary fat and calories.

\section{Definitions}

Dyslipidemia was defined by American Diabetes Association (ADA) as having Low density lipoprotein-cholesterol (LDL-C) $\geq$ $100 \mathrm{mg} / \mathrm{dl}$, high density lipoprotein-cholesterol (HDL-C) $<40 \mathrm{mg} / \mathrm{dl}$ (males) and $<50 \mathrm{mg} / \mathrm{dl}$ (females), total cholesterol (TC) $\geq 200 \mathrm{mg} / \mathrm{dl}$ and triglycerides (TG) $\geq 150 \mathrm{mg} / \mathrm{dl}$ [6] and that dyslipidemia is present if one or more of these lipid or lipoprotein levels are abnormal [7].

\section{Calculations}

Lipoprotein risk ratios were calculated as follows:

1. Atherogenic index of plasma (AIP) $=\log [$ TG/HDL-C $]$ : AIP $<0.11$ reflects low cardiovascular risk, AIP from 0.11 to 0.21 reflects intermediate risk and AIP $>0.21$ reflects high cardiovascular risk [8].

2. HDL-C/LDL-C ratio: it should be above 0.3 to stay away from any cardiovascular disorders [9].

3. Castelli index II (LDL-C/HDL-C): it should be below 3 [10].

4. Castelli index I (TC/HDL-C): it should be below 4 [10].

\section{Biochemical analysis}

Laboratory assessment for lipid profile will be done, after a 12-hr overnight fast, including: serum total cholesterol (TC) by cholesterol oxidase-peroxidase method, serum triglycerides (TG) by glycerokinaseperoxidase method, high density lipoprotein-cholesterol (HDL-C) by Stanbio HDL-C Procedure No. 0599 and low density lipoproteincholesterol (LDL-C)=TC $-($ HDL-C) $-(\mathrm{TG} / 5)$.

\section{Statistical analysis}

Data were statistically described in terms of mean \pm standard deviation $( \pm S D)$, median and range, or frequencies (number of cases) and percentages when appropriate. Comparison of numerical variables between the study groups was done using Mann Whitney $U$ test for independent samples. For comparing categorical data, Chi square $\left(\chi^{2}\right)$ test was performed. Exact test was used instead when the expected frequency is less than 5. P values less than 0.05 were considered statistically significant. All statistical calculations were done using computer programs SPSS (Statistical Package for the Social Science; SPSS Inc., Chicago, IL, USA) version 15 for Microsoft Windows.

\section{Results}

The sixty patients included 34 males (56.7\%) and 26 females $(43.3 \%)$. The mean age of the study group was $12.5 \pm 2.4$ years (range 9-19.5 years), the mean age at onset of DM was $8.2 \pm 2.6$ years (range 2.5-14.5 years), the mean duration of DM was $4.3 \pm 2.7$ years (range 1-12 years) and the mean insulin dose in the study group was $1.1 \pm 0.4$ $\mathrm{IU} / \mathrm{kg} /$ day (range 0.5-2.7 IU/kg/day).

Regarding the anthropometric measures of the study group using (Growth Vision 2.0), the mean for BMI SDS was $0.7 \pm 1.2$, and for the waist circumference was $77.9 \pm 12.6 \mathrm{~cm}$ (Table 1 ).

Thirty-eight patients of the study group (63.3\%) were of normal weight, 15 patients $(25 \%)$ were overweight $(<+1$ SDS) and 7 patients $(11.7 \%)$ were obese $(<+2$ SD). The mean BMI SDS $=0.7 \pm 1.2$.

Regarding the laboratory investigations; the mean values for fasting blood glucose (FBG), post prandial blood glucose (PPBG), HbA1c, the lipid profile were represented in Table 2 and showed slightly elevated LDL-C and high mean HbAlc of the study group.

Table 3 showed the pattern of dyslipidemia in the study group; no

\begin{tabular}{|c|c|c|c|}
\hline Anthropometry & Mean \pm Std. Deviation & Range & Median \\
\hline Wt SDS & $0.4 \pm 1.5$ & -1.9 to 7.5 & 0.0 \\
\hline Ht SDS & $-0.7 \pm 1.1$ & -4 to 3 & -0.5 \\
\hline BMI $\left(\mathrm{kg} / \mathrm{m}^{2}\right)$ & $20.7 \pm 4.9$ & $14.2-37.8$ & 19.5 \\
\hline BMI SDS & $0.7 \pm 1.2$ & -2 to 4 & 0.7 \\
\hline WC $(\mathrm{cm})$ & $77.9 \pm$ & $61-112$ & 74.5 \\
\hline
\end{tabular}

Wt: Weight. Ht: Height. BMI: Body mass index. SDS: Standard deviation score. WC: Waist circumference

Table 1: Anthropometric measures of the study group $(n=60)$.

\begin{tabular}{|c|c|c|c|}
\hline Labs & Range & Median & Mean \pm Std. Deviation \\
\hline Mean FBG (mg/dl) & $110-382$ & 200.1 & $205.4 \pm 56.5$ \\
\hline Mean 2hrs PPBG (mg/dl) & $83.2-364.3$ & 210.1 & $209.6 \pm 61.4$ \\
\hline Mean HbA1c (\%) & $6.1-13.2$ & 7.6 & $7.9 \pm 1.2$ \\
\hline TC $(\mathrm{mg} / \mathrm{dl})$ & $90-279$ & 164.5 & $165.8 \pm 38.8$ \\
\hline TG $(\mathrm{mg} / \mathrm{dl})$ & $20-253$ & 73.0 & $82.4 \pm 43$ \\
\hline HDL-C (mg/dl) & $16-141$ & 45.5 & $49.1 \pm 16.9$ \\
\hline LDL-C (mg/dl) & $37-189$ & 104.8 & $102 \pm 34.4$ \\
\hline
\end{tabular}

FBG: Fasting blood glucose. PPBG: Postprandial blood glucose. HbA1c: Glycosylated hemoglobin. TC: Total cholesterol. TG: Triglycerides. HDL-C: High density lipoprotein-Cholesterol. LDL-C: Low density lipoprotein-Cholesterol, Target FBG 90-145 mg/dl, PPBG 90-180 mg/dl, HbA1c $<7.5 \%$, TC $<200 \mathrm{mg} /$ $\mathrm{dl}$, TG $<150 \mathrm{mg} / \mathrm{dl}, \mathrm{HDL}-\mathrm{C}>40 \mathrm{mg} / \mathrm{dl}$ in males, $>50 \mathrm{mg} / \mathrm{dl}$ in females, LDL-C < $100 \mathrm{mg} / \mathrm{dl}$

Table 2: Laboratory investigations of the study group $(n=60)$

\begin{tabular}{|c|c|c|}
\hline Lipids & Frequency (number=60) & Percentage (\%) \\
\hline No abnormality & 21 & $35.0 \%$ \\
\hline High TC $(\mathrm{mg} / \mathrm{dl})$ & 11 & $18.3 \%$ \\
\hline High TG $(\mathrm{mg} / \mathrm{dl})$ & 5 & $8.3 \%$ \\
\hline Low HDL-C $(\mathrm{mg} / \mathrm{dl})$ & 23 & $38.3 \%$ \\
\hline High LDL-C $(\mathrm{mg} / \mathrm{dl})$ & 30 & $50.0 \%$ \\
\hline
\end{tabular}

TC: Total cholesterol. TG: Triglycerides. HDL-C: High density lipoproteinCholesterol. LDL-C: Low density lipoprotein-Cholesterol, Target TC $<200 \mathrm{mg} / \mathrm{dl}$, TG $<150 \mathrm{mg} / \mathrm{dl}$, HDL-C $>40 \mathrm{mg} / \mathrm{dl}$ in males, $>50 \mathrm{mg} / \mathrm{dl}$ in females, LDL-C $<100$ $\mathrm{mg} / \mathrm{dl}$

Table 3: Pattern of dyslipidemia in the study group. 
Citation: Hassan MM, Sharaf SA, Soliman HM, Al-Wakeel NA (2015) Dyslipidemia: A Cardiovascular Risk Factor in Type 1 Diabetes and Its Correlations. J Diabetes Metab 6: 586. doi:10.4172/2155-6156.1000586

Page 3 of 5

abnormality was detected in 21 patients (35\%) and 39 patients (65\%) were dyslipidemic. The most common abnormality was high LDL-C either alone or in combination with other parameters.

Regarding the different lipoprotein risk ratios, that are considered predictive values of cardiovascular risk, Table 4 showed the extent of the risk of CVD in the dyslipidemic patients. There were $46.2 \%$ of the dyslipidemic patients at risk of developing CVD according to TC/ HDL-C ratio (Castelli index I) and 20.5\% according to LDL-C/HDL-C ratio (Castelli index II).

Diet analysis of the study group revealed that the major component of their diet was the carbohydrate

then the protein followed by the fat. Calories from dietary fat of the study group were calculated and the mean was $445.7 \pm 173.0 \mathrm{Kcal} /$ day (Table 5).

Daily caloric needs were calculated and revealed that 43 patients (71.7\%) of the study group had normal caloric intake for age and sex while 17 patients $(28.3 \%)$ had increased caloric intake for age and sex (Table 6).

\section{Correlations between the lipid parameters, anthropometric measures, and different variables in the study}

Regarding TC of the patients, the correlation between TC and WC was on the threshold of significance ( $\mathrm{p}=0.056, \mathrm{r}=0.248)$, however, there were no significant correlations with the other variables (Figure 1). While, there was a positive significant correlation between TG with the age ( $\mathrm{p}=0.048, \mathrm{r}=0.256)$ but there were no significant correlations with the other variables (Figure 2).

As for HDL-C of the patients, there were no significant correlations with any of the variables (Figure 3 ). As regards LDL-C of the patients, there was a positive significant correlation with their BMI $(p=0.039$, $\mathrm{r}=0.268$ ) while the correlation with $\mathrm{WC}$ was of borderline significance $(\mathrm{p}=0.061, \mathrm{r}=0.243)$ but there were no significant correlations with the other variables (Figure 4).

Regarding BMI SDS of the patients, there was a strong positive significant correlation with their WC $(\mathrm{p}=0.000, \mathrm{r}=0.695)$ but there were

\begin{tabular}{|c|c|c|c|}
\hline \multicolumn{2}{|l|}{ Lipoprotein risk ratios } & \multirow{2}{*}{\begin{tabular}{|c|} 
Frequency \\
31
\end{tabular}} & \multirow{2}{*}{$\begin{array}{c}\text { Percent } \\
79.5 \%\end{array}$} \\
\hline \multirow{3}{*}{ AIP (log[TG/HDL-C]) } & Low risk $(<0.11)$ & & \\
\hline & $\begin{array}{l}\text { Intermediate risk } \\
(0.11-0.21)\end{array}$ & 4 & $10.2 \%$ \\
\hline & High risk (> 0.21) & 4 & $10.2 \%$ \\
\hline \multirow{2}{*}{ HDL-C/LDL-C ratio } & No risk $(>0.3)$ & 31 & $79.5 \%$ \\
\hline & At risk $(\leq 0.3)$ & 8 & $20.5 \%$ \\
\hline \multirow{2}{*}{$\begin{array}{l}\text { LDL-C/HDL-C ratio } \\
\qquad \text { (Castelli index II) }\end{array}$} & No risk $(<3)$ & 31 & $79.5 \%$ \\
\hline & At risk $(\geq 3)$ & 8 & $20.5 \%$ \\
\hline \multirow{2}{*}{$\begin{array}{l}\text { TC/HDL-C ratio } \\
\quad \text { (Castelli index I) }\end{array}$} & No risk $(<4)$ & 21 & $53.8 \%$ \\
\hline & At risk $(\geq 4)$ & 18 & $46.2 \%$ \\
\hline \multirow{5}{*}{$\begin{array}{l}\text { TC/HDL-C ratio } \\
\text { (Cholesterol risk chart) }\end{array}$} & Very low risk & 23 & $59.0 \%$ \\
\hline & Low risk & 9 & $23.1 \%$ \\
\hline & Average risk & 4 & $10.2 \%$ \\
\hline & High risk & 2 & $5.1 \%$ \\
\hline & Very high & 1 & $2.6 \%$ \\
\hline \multicolumn{4}{|c|}{$\begin{array}{l}\text { AIP: Atherogenic index of plasma } \\
\text { TC: Total cholesterol } \\
\text { TG: Triglycerides } \\
\text { HDL-C: High density lipoprotein-Cholesterol } \\
\text { LDL-C: Low density lipoprotein-Cholesterol }\end{array}$} \\
\hline
\end{tabular}

Table 4: Different lipoprotein risk ratios of the dyslipidemic patients (number= 39).

\begin{tabular}{|c|c|c|c|c|}
\hline Diet & Range & Median & Mean & Std. Deviation \\
\hline Fat in diet (gm/day) & $21.5-104.5$ & 45.2 & 49.5 & 19.2 \\
\hline CHO in diet (gm/day) & $127.1-542.4$ & 287.9 & 292.2 & 94.1 \\
\hline Protein in diet (gm/day) & $22-146.9$ & 65.2 & 63.5 & 23 \\
\hline Total calories (Kcal/day) & $797-3407.1$ & 1757.2 & 1821.3 & 532 \\
\hline Calories from fat (Kcal/day) & $193.8-940.7$ & 406.8 & 445.7 & 173 \\
\hline Daily fat intake (\%) & $14.3-45.5$ & 23.3 & 24.6 & 6.9 \\
\hline CHO: carbohydrate & & & & \\
\hline
\end{tabular}

Table 5: Diet analysis of the study group $(n=60)$.

\begin{tabular}{|l|l|l|l|}
\hline Diet & Frequency & Percent \\
\hline Total calories (Kcal/day) & Normal & 43 & $71.7 \%$ \\
\cline { 2 - 4 } & Increased & 17 & $28.3 \%$ \\
\hline Daily fat intake (\%) & $\begin{array}{l}\text { Normal* } \\
(<35.0 \% \text { of TDEI) }\end{array}$ & 54 & $90.0 \%$ \\
\hline $\begin{array}{l}\text { Increased } \\
(\geq 35.0 \% \text { of TDEI) }\end{array}$ & 6 & $10.0 \%$ \\
\hline
\end{tabular}

*This means that some of those with increased daily caloric intake have normal daily fat intake meaning probably more $\mathrm{CHO}$ intake

TDEI: Total daily energy intake

$\mathrm{CHO}$ : carbohydrate

Table 6: Frequency of normal or increased daily caloric and fat intake in the study group $(n=60)$.

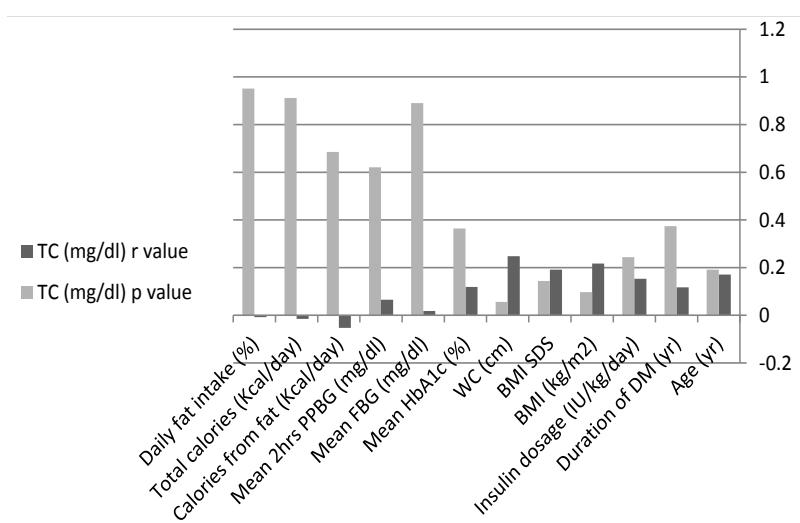

Figure 1: Correlations between total cholesterol (TC) and different variables in the study. TC: Total cholesterol. DM: Diabetes mellitus. BMI SDS: Body mass index standard deviation score. WC: Waist circumference. HbA1c: Glycosylated hemoglobin. BG: Blood glucose. FBG: Fasting blood glucose. PPBG: Postprandial blood glucose.

no significant correlations with the other variables (Figure 5). As for $\mathrm{WC}$ of the patients, there were strong positive significant correlations with their BMI and BMI SDS $(\mathrm{p}=0.000, \mathrm{r}=0.770)$ and $(\mathrm{p}=0.000$, $\mathrm{r}=0.695)$ respectively and insulin dosage $(\mathrm{p}=0.045, \mathrm{r}=0.260)$ while the correlations with TC and LDL-C were of borderline significance $(\mathrm{p}=0.056, \mathrm{r}=0.248)$ and $(\mathrm{p}=0.061, \mathrm{r}=0.243)$ respectively but there were no significant correlations with the other variables (Figure 6).

\section{Discussion}

In the current study, the most frequent type of dyslipidemia was high LDL-C. This in contrast to Moayeri and Oloomi and Alrabaty et al. who found that the most frequent type is isolated hypertriglyceridemia $[11,12]$. However it was found to be the least common type in Patiakas et al. study [13]. These differences may be related to different glycemic control across the studies or different genetic or ethnic factors.

In the current study, there was a positive significant correlation 
Citation: Hassan MM, Sharaf SA, Soliman HM, Al-Wakeel NA (2015) Dyslipidemia: A Cardiovascular Risk Factor in Type 1 Diabetes and Its Correlations. J Diabetes Metab 6: 586. doi:10.4172/2155-6156.1000586

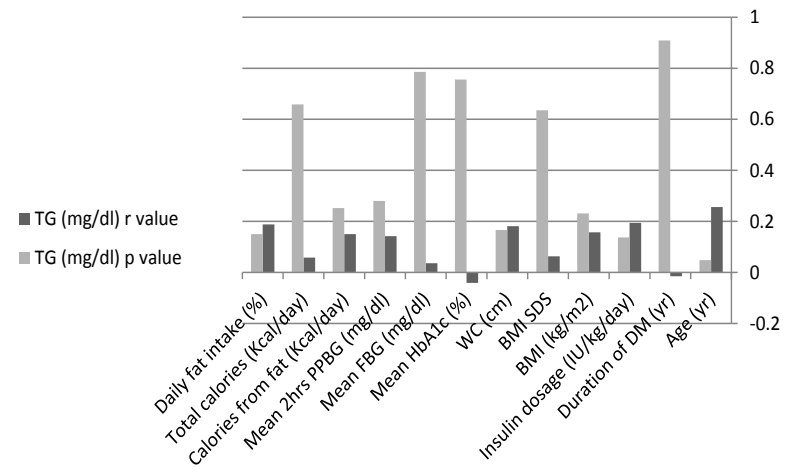

Figure 2: Correlation between Triglycerides (TG) and different variables in the study. TG: Triglyceride. DM: Diabetes mellitus. BMI SDS: Body mass index standard deviation score. WC: Waist circumference. HbA1c: Glycosylated hemoglobin. BG: Blood glucose. FBG: Fasting blood glucose. PPBG: Postprandial blood glucose

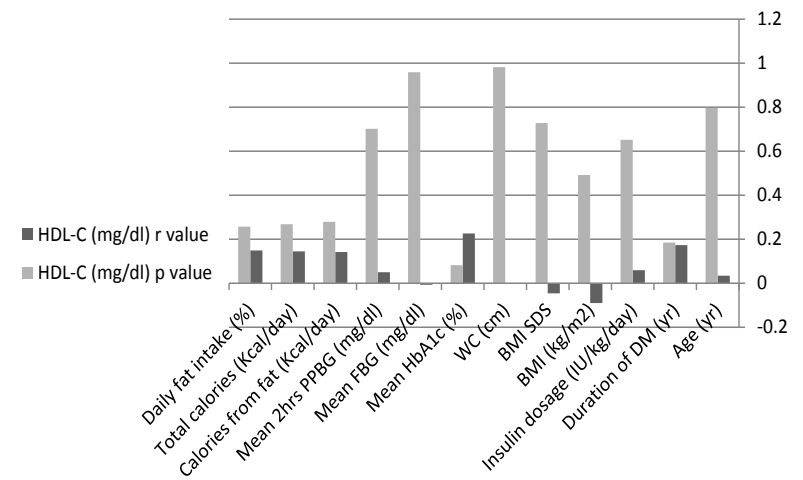

Figure 3: Correlation between HDL-C and different variables in the study. HDL-C: High density lipoprotein-Cholesterol. DM: Diabetes mellitus. BMI SDS: Body mass index standard deviation score. WC: Waist circumference. HbA1c: Glycosylated hemoglobin. BG: Blood glucose. FBG: Fasting blood glucose. PPBG: Postprandial blood glucose.

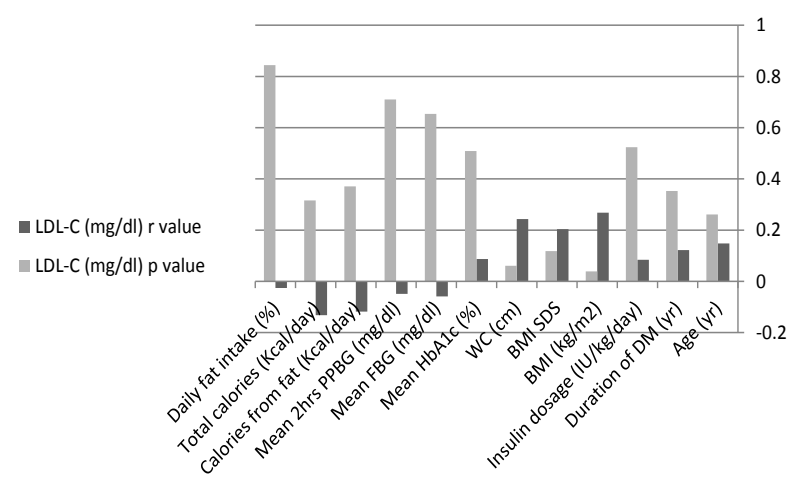

Figure 4: Correlation between LDL-C and different variables in the study. LDL-C: Low density lipoprotein-Cholesterol. DM: Diabetes mellitus. BMI SDS: Body mass index standard deviation score. WC: Waist circumference. HbA1c: Glycosylated hemoglobin. BG: Blood glucose. FBG: Fasting blood glucose. PPBG: Postprandial blood glucose.

between BMI of the diabetics and LDL-C. This does not agree with Alrabaty et al., who found that LDL-C was not influenced significantly by BMI among children and adolescents with T1DM [12]. However, the correlation between BMI of the diabetics and insulin dose was of borderline significance in agreement with Ladeia et al, who found that BMI correlates positively with insulin daily doses [14].

Serum TC, TG, and serum HDL-C levels showed no statistically significant correlations with BMI SDS. However, the correlations between WC of diabetics and levels of TC and LDL-C were of borderline significance $(\mathrm{p}=0.056)$ and $(\mathrm{p}=0.061)$ respectively. There were no significant correlations between WC of the diabetics and mean HbA1c or serum TG in contrast to Teles and Fornés who found that WC of the patients correlates positively with $\mathrm{HbA1c}$ and serum TG in children and adolescents with T1DM [15].

There were no significant correlations between mean $\mathrm{HbAlc}$ and serum TC, TG, LDL-C or BMI; this seems to contradict with Rahma et al. and Al-Naama et al. who found that these lipid concentrations correlate positively with $\mathrm{HbA1c}$ levels in children and adolescents with T1DM $[16,17]$. Serum HDL-C of the diabetics in this study doesn't have any significant correlation with mean $\mathrm{HbAlc}$; this is in concordance with Maahs et al. and Rahma et al. $[18,16]$. This may be attributed to the insignificant differences in the HbAlc among the study group and even between dyslipidemic and normolipidemic groups as most of the patients had optimal or suboptimal HbAlc.

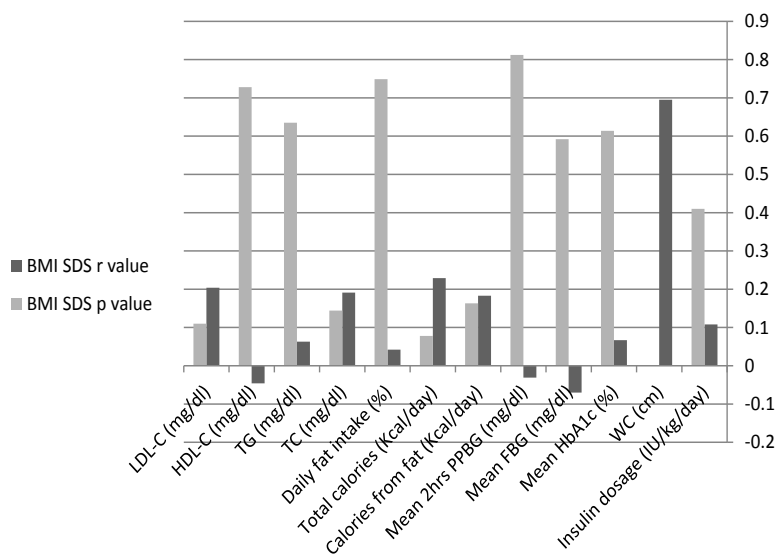

Figure 5: Correlation between BMI SDS and different variables in the study. BMI SDS: Body mass index standard deviation score. WC: Waist circumference. HbA1c: Glycosylated hemoglobin. BG: Blood glucose. FBG: Fasting blood glucose. PPBG: Postprandial blood glucose. TC: Total cholesterol. TG: Triglycerides. HDL-C: High density lipoprotein-Cholesterol. LDL-C: Low density lipoprotein-Cholesterol.

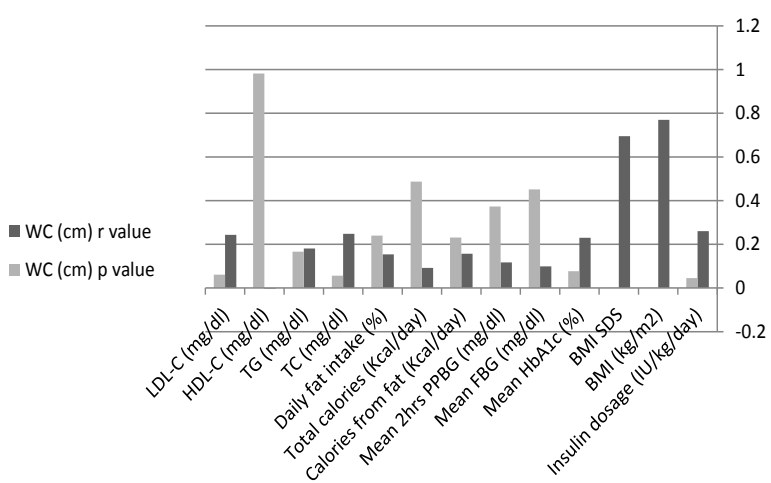

Figure 6: Correlation between waist circumference (WC) and different variables in the study. WC: Waist circumference. BMI SDS: Body mass index standard deviation score. HbA1c: Glycosylated hemoglobin. BG: Blood glucose. FBG: Fasting blood glucose. PPBG: Postprandial blood glucose. TC: Total cholesterol. TG: Triglycerides. HDL-C: High density lipoproteinCholesterol. LDL-C: Low density lipoprotein-Cholesterol. 
Citation: Hassan MM, Sharaf SA, Soliman HM, Al-Wakeel NA (2015) Dyslipidemia: A Cardiovascular Risk Factor in Type 1 Diabetes and Its Correlations. J Diabetes Metab 6: 586. doi:10.4172/2155-6156.1000586

Page 5 of 5

The correlations between FBG and PPBG with serum TC, TG, HDL-C and LDL-C were insignificant in agreement with Teles and Fornés, and Abraham and Anne [15,19].

In the present study, there were $18(46.2 \%)$ of the dyslipidemic group at risk of developing CVD according to TC/HDL-C ratio (Castelli index I) and 8 (20.5\%) of them were at CVD risk according to LDL-C/HDL-C ratio (Castelli index II). This finding is in agreement with Rahma et al and Al-Naama et al which found increased risk of atherosclerosis according to LDL-C/HDL-C ratio $[16,17]$.

\section{Limitations}

The limitations of this study derive from its cross-sectional design. Thus, we should recall the possible variations over time in the parameters studied. The sample size was the result of applying strict criteria for the selection of patients and excluding patients who received specific diet or medical management for dyslipidemia or other medical problems or medications that may affect the lipid profile or if the patient was non-compliant to follow up and SBGM as all this can affect the full assessment of the glycemic control and the relation of the mean fasting and post prandial blood glucose on different lipid parameters.

\section{Conclusion}

The most frequent type of dyslipidemia was high LDL-C alone or in combination with other parameters in $50 \%$ of children and adolescents with T1DM and dyslipidemia. There were $46.2 \%$ of dyslipidemic patients at risk of developing CVD according to total cholesterol (TC)/ HDL-C ratio (Castelli index I) and $20.5 \%$ of them were at CVD risk according to LDL-C/HDL-C ratio (Castelli index II). There was a positive correlation between LDL-C and BMI and WC.

\section{Disclosure Statement}

Authors have no conflict of interest to disclose.

\section{Acknowledgment}

We would like to thank all children and their parents who participated in this work. We would like to express our appreciation to our colleagues and nurses at The Diabetes Endocrine and Metabolism Pediatric Unit (DEMPU) who facilitated this work. At last but not least, l'd like to thank all the members of the Editorial Advisory Board for their careful review.

\section{References}

1. Donaghue KC, Wadwa RP, Dimeglio LA, Wong TY, Chiarelli F, et al. (2014) ISPAD Clinical Practice Consensus Guidelines 2014. Microvascular and macrovascular complications in children and adolescents. Pediatr Diabetes 15 Suppl 20: 257-269.

2. Hamad A, Qureshi HJ (2008) Dyslipidaemia in recently diagnosed young subjects of type 1 diabetes mellitus with normal/favourable BMI: a risk factor of macrovascular disease. Biomedica 24: 130-3.

3. Wadwa RP, Kinney GL, Maahs DM, Snell-Bergeon J, Hokanson JE, et al
(2005) Awareness and treatment of dyslipidemia in young adults with type 1 diabetes. Diabetes Care 28: 1051-1056.

4. Gotto AM Jr (2011) Jeremiah Metzger Lecture: cholesterol, inflammation and atherosclerotic cardiovascular disease: is it all LDL? Trans Am Clin Climato Assoc 122: 256-289.

5. de Onis M, Onyango AW, Borghi E, Siyam A, Nishida C, et al. (2007) Development of a WHO growth reference for school-aged children and adolescents. Bull World Health Organ 85: 660-667.

6. Wysham C, Austin R, Braithwaite S, Funnell M, Gabbay R, et al. (2012) Standards of medical care in diabetes-2012. Diabetes Care 35: S11-63.

7. Kwiterovich PO Jr (2008) Recognition and management of dyslipidemia in children and adolescents. J Clin Endocrinol Metab 93: 4200-4209.

8. Dobiásová M, Frohlich J (2001) The plasma parameter log (TG/HDL-C) as an atherogenic index: correlation with lipoprotein particle size and esterification rate in apoB-lipoprotein-depleted plasma (FER(HDL)). Clin Biochem 34: 583588.

9. Gowtham K, Gandhe MB, Salwe KJ, Srinivasan AR (2012) HDL/LDL ratio as a risk factor in type 2 diabetes mellitus. Adv Lab Med Int 2: 9-18.

10. Jamil S, Siddiq A (2012) Comparison of CVD risk associated with the long term use of contraceptives in young females. JAPS 2: 062-6.

11. Moayeri H, Oloomi Z (2006) Prevalence of dyslipidemia in children and adolescents with diabetes mellitus type I. Iran J Pediatr 16: 171-6.

12. Alrabaty AA, Alnakshabandi AA, Yahya NB (2009) The lipid profile in children with type 1 diabetes mellitus in Erbil governorate. The Iraqi postgraduate medical journal 8: 344-9.

13. Patiakas S, Kiriakopoulos N, Gavala C, Aggos I, Akritopoulou K, et al. (2007) The lipid profile of patients with diabetes mellitus in Paionia country. Diabetol Stoffwechs 2: 35.

14. Ladeia AM, Adan L, Couto-Silva AC, Hiltner A, Guimarães AC (2006) Lipid profile correlates with glycemic control in young patients with type 1 diabetes mellitus. Prev Cardiol 9: 82-88.

15. Teles SA and Fornés NS (2012) Relationship between anthropometric and biochemical profiles in children and adolescents with type 1 diabetes. Rev Paul Pediatr 30: 65-71.

16. Rahma S, Rashid JA, Farage AH (2006) The significance of lipid abnormalities in children with insulin dependent diabetes mellitus. The Iraqi postgraduate medical journal 5: 289-94.

17. al-Naama LM, Kadhim M, al-Aboud MS (2002) Lipid profile in children with insulin dependent diabetes mellitus. J Pak Med Assoc 52: 29-34.

18. Maahs DM, Wadwa RP, McFann K, Nadeau K, Williams MR, et al. (2007) Longitudinal lipid screening and use of lipid-lowering medications in pediatric type 1 diabetes. J Pediatr 150: 146-150, 150.

19. Abraham L, Anne M (2000) The lipid profile of diabetic patients at the diabetes clinic of the Philippine general hospital. Philippine J Intern Med 38: 16-20. 